Colino, Alberto. Evolución de la financiación de los medios de comunicación en España. ¿Hacia un modelo más sostenible?

\title{
EVOLUCIÓN DE LA FINANCIACIÓN DE LOS MEDIOS DE COMUNICACIÓN EN ESPAÑA. ¿HACIA UN MODELO MÁS SOSTENIBLE?
}

\section{EVOLUTION OF FUNDING TO MASS MEDIA IN SPAIN. TOWARDS A MORE SUSTAINABLE MODEL?}

\author{
ALBERTO COLINO FERNÁNDEZ \\ Universidad Pontificia Comillas \\ acolino@cee.upcomillas.es
}

Fecha de recepción: febrero de 2013

Fecha de aceptación: mayo de 2013

\begin{abstract}
RESUMEN
El acceso a la información es un derecho que nuestra Constitución reconoce y protege como un derecho fundamental de todas las personas. Desde esta perspectiva, las ayudas del Estado a los medios de comunicación tienen un fundamento que las justifica como medio de garantizar la disposición de un número suficiente de medios plurales al alcance de los ciudadanos. No obstante, detractores de las mismas arguyen que suponen un despilfarro de recursos -ya que el mercado se encarga de que sobrevivan los más eficientes- y la injerencia del Gobierno de turno sobre los medios informativos. Así, este artículo se encarga de analizar los cambios acontecidos en la evolución del modelo de financiación de los medios de comunicación en España en los últimos años, y en particular la creciente importancia de la partida de subvenciones, para así poder caracterizar su estado actual y la idoneidad del mismo en la empresa de conseguir los objetivos que persigue.
\end{abstract}

PALABRAS CLAVE: medios de comunicación, financiación, subsidios.

\section{ABSTRACT}

The access to information is a right that our Constitution recognizes and protects as a fundamental right of every person. From this standpoint, Government subsidies to mass media have a foundation that justifies them as a mean to guarantee the provision of a sufficient number of plural media available to citizens. Nevertheless, detractors of subsidies argue that they entail a waste of resources -since the market guarantees that the most efficient will survive- and the interference of the Government of the moment on mass media. Therefore, this article analyses the changes happened in the evolution of the funding model of mass media in Spain in recent years, and particularly the increasing relevance of subsidies, in order to be able to characterize its current condition and suitability to achieve the goals that it pursues.

KEYWORDS: mass media, funding, subsidies.

JEL: H25. 
Colino, Alberto. Evolución de la financiación de los medios de comunicación en España. ¿Hacia un modelo más sostenible?

\section{INTRODUCCIÓN}

El modelo de financiación de los medios de comunicación en España, tanto privados como públicos, ha sufrido una profunda transformación en los últimos años. Por un lado, por los cambios acontecidos en la legislación a este respecto desde que en los años setenta y ochenta comenzaran a otorgarse ayudas públicas a los medios de comunicación (Blasco Gil, 2008: 95-103) hasta que a comienzos de los años 2000 las ayudas quedaran en manos de los gobiernos autonómicos y se adjudicaran principalmente por motivos lingüísticos y posteriormente en 2010 entrara en vigor del nuevo modelo de financiación aprobado por el anterior Gobierno.

Por otro lado, como consecuencia de la actual crisis económica, que está reduciendo el principal canal de ingresos de las cadenas, la publicidad, y que afectó el año pasado especialmente a las televisiones autonómicas y locales públicas, que son las que todavía emiten publicidad, ya que TVE dejó de hacerlo a finales de 2009 con la entrada en vigor de la Ley 8/2009 que suprimía la publicidad en la Corporación de Radio y Televisión Española (CRTVE).

Especial interés tiene la cuestión de las ayudas públicas a los medios de comunicación, ya que las subvenciones son una necesidad no exenta de polémica por el control que se ejerce sobre ellos. Como señalan los profesores Quintana y Oliva (2012): "Las ayudas del Estado a los medios de comunicación siempre han generado controversia desde los distintos ámbitos de la Sociedad de la Información. Desde antaño, las subvenciones a la prensa han tenido defensores y detractores. Los primeros, porque las han considerado como una exigencia para la persistencia de la información; los segundos, porque las han calificado como una corrupción del desarrollo informativo, auspiciado por el Gobierno que ostente el poder."

Es bien sabido, que los medios son utilizados para la consecución de objetivos que trascienden la comunicación objetiva según diversos intereses económicos, políticos y sociales. Así, que un periódico, canal de televisión o emisora de radio privada e "independiente" reciba financiación pública, no deja de ser un asunto de gran controversia.

Como ya hemos señalado, en España en los últimos años las mismas se han circunscrito mayoritariamente al ámbito autonómico. Así, según la Secretaría de Estado de Comunicación, "los Presupuestos Generales del Estado ya no consideran la asignación de ninguna partida destinada a ayudas a empresas periodísticas ni a agencias informativas" y han dejado esta actividad en manos de los Gobiernos de las Comunidades Autónomas, "que tienen atribuida esta facultad en la medida en que posibiliten la promoción de su realidad lingüística, es decir, el uso y conocimiento de su idioma propio" (Morales, 2006: 105).

Cabe matizar, no obstante, estas dos afirmaciones. Por una parte, el Ministerio de Cultura concede anualmente subvenciones a revistas de temática cultural. Por otra parte, si bien es cierto que las Comunidades Autónomas concentran las subvenciones a la prensa en España, es importante destacar que, aunque la mayoría se justifican por razones lingüísticas, también existen subsidios en comunidades sin lengua propia, así como ayudas que no se conceden por motivos lingüísticos en comunidades que cuentan con dos lenguas co-oficiales. 
Colino, Alberto. Evolución de la financiación de los medios de comunicación en España. ¿Hacia un modelo más sostenible?

Es por esto que el presente trabajo se encarga de analizar la evolución de las distintas fuentes de financiación de los medios de comunicación en España en los últimos años. Así, el siguiente apartado presenta las principales modificaciones que a nivel legislativo han ocurrido en lo que se refiere a las ayudas públicas a los medios de comunicación. Posteriormente, se analizará la composición y desarrollo reciente de la financiación de los medios de comunicación, tanto privados como públicos, en España. Finalmente, se ofrecerán a modo de conclusiones algunos comentarios sobre la sostenibilidad del modelo de financiación seguido en los últimos años en nuestro país y las perspectivas futuras.

\section{AYUDAS PÚBLICAS A LOS MEDIOS DE COMUNICACIÓN}

Como se ha comentado con anterioridad, ya en los años setenta y ochenta comenzaron a otorgarse ayudas públicas a los medios de comunicación. Así, en una primera etapa, hasta 1983, las ayudas tenían un marcado carácter discrecional (Fernández y Santana, 2000: 70-71) y se llegaron a repartir el equivalente a cuatro millones de euros. Más tarde, la Ley 29/1984, reguladora de la concesión de ayudas a empresas periodísticas y agencias informativas estableció un modelo reglado de ayudas directas e indirectas al sector, inmerso todavía en la crisis de los setenta, con plantillas sobredimensionadas, altos costes de producción, necesitado de una renovación tecnológica, con elevadas deudas con el Estado y en un contexto de muy bajos índices de lectura (Morales, 2006: 106).

En opinión del profesor Justino Sinova (1999: 240), "a lo largo de la historia de los medios las ayudas que la Administración ha prestado forman una larga relación". Las ayudas públicas son las que se han conocido en los ámbitos empresariales, divididas en directas e indirectas:

a) Ayudas directas, que suponen un ingreso monetario en la empresa, realizado gratuitamente por el Estado, sin contraprestación. Entre ellas, se encuentran:

- Subvención para adquisición de papel-prensa u otros productos.

- Subvenciones para renovación tecnológica.

- Subvenciones para nuevos productos o nuevas actividades.

- Subvención por ejemplares difundidos, taquillajes, etc.

- Subvención por difusión en el extranjero.

- Subvención por participación en objetivos políticos, campañas, etc.

b) Ayudas indirectas, cuando el beneficio de la ayuda no lo recibe directamente la empresa periodística, o cuando el Estado deja de percibir un ingreso que corresponde hacer a la empresa:

- Reducción o exoneración de impuestos.

- Reducción de tarifas postales, telegráficas y telefónicas.

- Créditos oficiales baratos.

- Subvenciones a fabricantes de papel-prensa.

- Estímulos económicos a fabricantes de maquinaria de artes gráficas.

- Beneficios económicos en favor del personal de la empresa periodística.

- Subvenciones a instituciones corporativas de la Prensa.

- Control de los ingresos publicitarios de los medios públicos.

- Reducción de coste de los servicios de agencias informativas públicas.

- Campañas en favor del consumo de medios de comunicación.

- Limitación de difusión de productos extranjeros. 
Colino, Alberto. Evolución de la financiación de los medios de comunicación en España. ¿Hacia un modelo más sostenible?

De este modo, las principales modalidades de ayudas directas se otorgaron en concepto de apoyo a la difusión, al consumo de papel prensa nacional y a la reconversión tecnológica. Ya en el año 1988, tras el ingreso de España en la Comunidad Europea (CE), las autoridades comunitarias advirtieron al Gobierno español de que su pertenencia a la CE exigía la supresión de las ayudas al papel prensa de producción nacional, porque contravenía la normativa sobre competencia. ${ }^{1}$ Fue entonces cuando el Gobierno derogó parcialmente la normativa sobre ayudas a la prensa mediante la Ley 37/1988.

Pero el Ejecutivo fue más allá de las demandas comunitarias y suprimió todas las modalidades de ayudas directas existentes entonces -excepto, obviamente, la publicidad institucional, basándose en la mejoría económica del sector, que había alcanzado incrementos notables de los beneficios, de la inversión publicitaria y de la difusión (Fernández y Blasco, 2006).

Posteriormente, ya a comienzos de los años noventa, a través de la Ley 31/1990, se suprimió la mayoría de las ayudas indirectas, de forma que en 2007, en España, únicamente pervivían las relativas al franqueo postal, que tienen una mínima repercusión, porque la mayoría de las empresas cuenta con su propia distribuidora, y un IVA del $4 \%$ sobre la venta al número.

Desde comienzos de los años 2000 las mismas se han circunscrito al ámbito autonómico. Así, según la Secretaría de Estado de Comunicación, "los Presupuestos Generales del Estado ya no consideran la asignación de ninguna partida destinada a ayudas a empresas periodísticas ni a agencias informativas" y han dejado esta actividad en manos de los Gobiernos de las Comunidades Autónomas, "que tienen atribuida esta facultad en la medida en que posibiliten la promoción de su realidad lingüística, es decir, el uso y conocimiento de su idioma propio" (Morales, 2006: 105).

Como veremos más adelante, si bien es cierto que la mayoría de las subvenciones se atribuyen por razones lingüísticas, también lo es que en comunidades sin lengua propia, como Andalucía, y también en las que cuentan con dos lenguas oficiales, se apela a otros motivos.

Como señalan de la Quintana y Oliva (2012) tras consultar los Boletines Oficiales de las Comunidades Autónomas de Andalucía, Cataluña, Galicia y El País Vasco, las subvenciones concedidas a la prensa responden a seis premisas básicas:

- El fortalecimiento de las ayudas a publicaciones periódicas publicadas en las lenguas co-oficiales de las Comunidades Autónomas de Cataluña, Galicia y EI País Vasco.

- El fomento de la lectura.

- El auge del periodismo especializado.

- La diversidad de subvenciones según corresponda a publicaciones de pago o gratuitas.

\footnotetext{
1 Para un tratamiento más detallado de las ayudas públicas a nivel de la Unión Europea ver por ejemplo, Fernández y Blasco (2006) o Humphreys (2008).
} 
Colino, Alberto. Evolución de la financiación de los medios de comunicación en España. ¿Hacia un modelo más sostenible?

- La periodicidad de las publicaciones periódicas (diaria, semanal, quincenal y mensual).

- La cobertura de las publicaciones (local, nacional).

En cuanto a los medios de comunicación públicos de radio y televisión, la Ley 17/2006, de 5 de junio creó la «Corporación de Radio y Televisión Española, S.A.» y el 1 de enero de 2007 nació la Corporación RTVE. Así, el Parlamento aprobó la constitución de esta entidad que gestiona la radio y televisión pública españolas.

De este modo, la Ley 17/2006, de la radio y televisión de titularidad estatal, supuso una importante reforma del sector audiovisual de titularidad estatal en la línea de lo establecido en el Protocolo 32 del Tratado de Constitución de la Comunidad Europea sobre el sistema de radiodifusión de los Estados miembros. Esta ley creó la Corporación RTVE dotándola de un régimen jurídico moderno acorde con los tiempos y los avances tecnológicos producidos en el sector. La definición del servicio público de radio, televisión y servicios conexos e interactivos así como la encomienda de su prestación a la naciente Corporación constituían una necesidad, una exigencia, que dicho texto legal vino a satisfacer.

Según la ley de la radio y la televisión de titularidad estatal, la Corporación tiene la gestión del servicio público de radio y televisión. Es una sociedad mercantil estatal con especial autonomía e independencia del Gobierno y de la Administración General del Estado que ejerce sus funciones mediante TVE y RNE. Su administración y gobierno, en virtud del artículo 9, punto 2, corresponde a un Consejo de Administración que desarrolla sus funciones ejecutivas a través de su Presidente, que presidirá la Corporación. Pero la independencia política constituyó sólo uno de los pilares de la reforma. El otro lo constituyó la independencia económica, hacia la que la ley también dio pasos.

Estableció para la nueva Corporación un modelo de financiación mixta -que combinaba los ingresos procedentes de los Presupuestos Generales del Estado, fijados cada tres años en un contrato-programa, con los derivados de su participación en el mercado publicitario- bajo el principio de equilibrio presupuestario. Pero la fórmula de combinación de ingresos públicos con comerciales no es libre. Primero, la nueva Directiva Europea 2007/65/CE del Parlamento Europeo y del Consejo de 11 de diciembre, mantuvo el límite de doce minutos por hora de reloj para la emisión de publicidad. Segundo, el artículo 32.2 de la Ley 17/2006 estableció que «el contrato-programa deberá incorporar restricciones adicionales a las establecidas con carácter general en la Ley 25/1994 de 12 de julio, para la emisión de publicidad televisiva». Y, además, esa previsión de restricciones adicionales se reiteró en el mandato-marco para la CRTVE aprobado por las Cortes en diciembre de 2007.

La Ley 8/2009, de 28 de agosto, de financiación de la Corporación de Radio y Televisión Española estableció que "el actual estado de cosas aconseja acelerar el proceso de cambio estructural del modelo de financiación de RTVE, renunciar definitiva e inmediatamente a los ingresos publicitarios y pasar a un sistema único de financiación basado en ingresos públicos, amortiguando situaciones de inestabilidad propias de los procesos de transición y consiguiendo que los efectos de la reducción publicitaria en RTVE se dejen sentir lo antes posible en el mercado televisivo." 
Colino, Alberto. Evolución de la financiación de los medios de comunicación en España. ¿Hacia un modelo más sostenible?

Sin embargo, la supresión de los ingresos procedentes de la publicidad hubo de implementarse junto a otras medidas destinadas a garantizar legalmente que la Corporación RTVE fuera compensada suficientemente con los ingresos públicos que le permitan seguir prestando el servicio público encomendado en la ley y el mandato-marco, pero sin dejar de cumplir con el principio de equilibrio presupuestario.

De este modo, la Ley 8/2009 plantea un sistema de financiación en el cual la garantía de la financiación es a costa de aumentar las aportaciones del Estado. Simultáneamente, aquellos que resultaban beneficiados por esta decisión deberían también soportar, en parte, esa carga económica. Así, se establecía la imposición de una aportación razonable a las operadoras privadas para la financiación de la televisión pública que, por otro lado, es una fórmula utilizada por otros países de nuestro entorno.

Esta aportación proveniente las operadoras privadas de televisión y telecomunicaciones no podía hacerse cargo de la totalidad de los ingresos que la Corporación RTVE dejaba de percibir por su renuncia al mercado publicitario y a los contenidos de pago ya que, de ser así, no se conseguiría el efecto dinamizador del sector que también pretendía esta medida. Por ello se optó por aplicar, al igual que en otros países de nuestro entorno, un porcentaje sobre los ingresos de los operadores del $3 \%$ para los de televisión comercial en abierto, del 1,5\% para los operadores de televisión de pago y del 0’9\% para los de telecomunicaciones.

Además, como se indica en la propia norma, se creó un fondo de reserva, dotado con los ingresos que superen el coste neto del servicio público que se preste, bien para atender a situaciones sobrevenidas o bien para reducir las aportaciones directas del Estado vía Presupuestos Generales.

En la actualidad, las ayudas se circunscriben principalmente al ámbito autonómico, así que resulta interesante ver algo más en detalle las características particulares de las ayudas concedidas por los Gobiernos de las Comunidades Autónomas en aquellas con lengua propia y otras sin lengua propia.

\subsection{Cataluña}

En Cataluña, la desventaja competitiva de los medios de comunicación en catalán es el motivo que se esgrime para considerar pertinentes las ayudas a estos medios de lengua catalana. Entre las características que debe cumplir una publicación para ser subvencionada por la Generalitat se encuentra que debe "estar editada en un $100 \%$ en catalán o en aranés, o tener ediciones en estas lenguas, con independencia de que puedan incluir la traducción a otras."

En marzo de 2013, se publicó en el diario El País que el Departamento Autonómico de Presidencia había convocado una nueva ronda de subvenciones a fondo perdido para los medios de comunicación privados de todo tipo, desde medios impresos a diarios digitales, pasando por radios y televisiones. Así, se subrayaba que el presupuesto a repartir ascendía a 9,4 millones de euros, lo que suponía un ascenso de más de 3 millones de euros respecto al año anterior. 
Colino, Alberto. Evolución de la financiación de los medios de comunicación en España. ¿Hacia un modelo más sostenible?

En concreto, según recoge el Diario Oficial de la Generalidad de Cataluña (DOGC), la Generalitat otorgará 3.194 .000 euros a publicaciones periódicas (diarias y no diarias) en soporte papel (PRE/1314/2012); 1.270 .979 euros (ampliables en otros 666.000 euros) a proyectos que fomenten y consoliden el espacio catalán de comunicación para empresas periodísticas privadas editoras de prensa en soporte de papel (PRE/1303/2012); 855.000 euros a medios informativos digitales de titularidad privada (PRE/1300/2012); 777.000 euros a emisoras de televisión digital terrestre de empresas privadas para proyectos que fomenten y consoliden el espacio catalán de comunicación (PRE/1308/2012); 763.000 euros a proyectos que fomenten y consoliden el espacio catalán de comunicación para empresas periodísticas privadas editoras de prensa digital (PRE/1307/2012); 713.000 euros a emisoras de radio de empresas privadas para proyectos que fomenten y consoliden el espacio catalán de comunicación (PRE/1306/2012); 550.000 euros a emisoras de radio de titularidad privada (PRE/1299/2012); 400.000 euros a emisoras de televisión de titularidad privada (PRE/1310/2012); y 280.000 euros a entidades sin ánimo de lucro para proyectos que contribuyan al fomento del periodismo y del espacio catalán de comunicación (PRE/1309/2012).

De este modo, la cifra presupuestaria destinada a medios catalanes se ha ampliado en 666.000 euros, estableciendo un total de 1.936.979 euros. El Boletín Oficial de la Generalitat Catalana (BOGC) explica esta ampliación como una concesión de subvenciones "a proyectos que fomenten y consoliden el espacio catalán de comunicación para las empresas periodísticas privadas editoras de prensa en soporte papel correspondiente al año 2012".

Así, el conglomerado mediático más beneficiado por las aportaciones de la Generalitat fue el Grupo Godó, editor de La Vanguardia (desde 2011, con edición bilingüe) y El Mundo Deportivo (en castellano), propietario de la emisora privada generalista RAC1, de la musical RAC105 y de la cadena de televisión 8TV, que recibió en el 2011 el $40 \%$ de las subvenciones concedidas por la Generalitat a los medios catalanes. El grupo recibió en 2012 un total de 1,45 millones en subvenciones. De ellos, 445.000 euros supusieron la inversión estructural en La Vanguardia en catalán, rotativo que recibió, en concepto de proyectos, 178.000 euros para mejorar su edición catalana y 40.000 euros para implementar ediciones locales. El Mundo Deportivo recibió 100.000 euros para un suplemento en catalán.

El segundo grupo en importe de subvenciones fue el grupo Hermes, editor de los diarios El Punt-Avui y el deportivo El Nou Esportiu. De este modo, la fusión de los generalistas Avui y El Punt ha supuesto un importante auge en las subvenciones de este rotativo, el cuarto más leído de Cataluña, por detrás de El País, tercero. El diario recibió una subvención estructural total de 490.000 euros, ya que cobró por su edición catalana y por su edición de la provincia de Girona. Este importe fue superior a la subvención estructural de La Vanguardia y El Periódico. Además, El Punt-Avui se embolsó 477.000 euros más en proyectos: la mitad, para una campaña promocional de la fusión. En 2011, con ambos rotativos separados, el desembolso público en Avui, El Punt, y El Nou Esportiu fue de 878.887 euros.

El grupo Zeta, editor de múltiples soportes, solo recibió subvenciones para El Periódico, que se edita en catalán y castellano. Pero el rotativo acumuló 1,09 
Colino, Alberto. Evolución de la financiación de los medios de comunicación en España. ¿Hacia un modelo más sostenible?

millones de euros. A la estructural de 442.373 euros se sumaron 466.000 euros para un proyecto de innovación tecnológica y otro de integración de la redacción.

\subsection{País Vasco}

El artículo 10 del Decreto 20/2012, de 15 de diciembre, del Lehendakari, de creación, supresión y modificación de los Departamentos de la Administración de la Comunidad Autónoma del País Vasco y de determinación de funciones y áreas de actuación de los mismos, asignó al Departamento de Educación, Política Lingüística y Cultura, entre otras, las relativas a la política lingüística y a la promoción del euskera.

Por otro lado, el artículo 14.2.e) del Decreto 45/2011, de 22 de marzo, por el que se establece la estructura orgánica del Departamento de Cultura (BOPV de 25 de

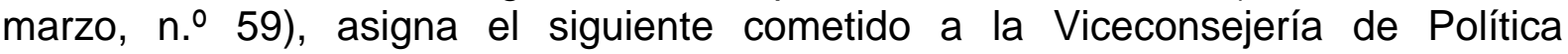
Lingüística: "velar por el adecuado desarrollo y aplicación de la Ley 10/1982, Básica de Normalización del Uso del Euskera y demás disposiciones complementarias, sin perjuicio de las funciones que en tal sentido tengan específicamente asignados otros órganos administrativos."

Asimismo, la Viceconsejería de Política Lingüística asume las líneas de prioridad para la política lingüística de principios del siglo XXI formuladas por el Consejo Asesor del Euskera, recogidas en la publicación «Euskara 21. Hacia un Pacto Renovado». Dicho Consejo aprobó en julio de 2012 el Plan de Acción para la Promoción del Euskera (ESEP), el cual elabora las líneas prioritarias recogidas en «Euskara 21. Hacia un pacto renovado», adaptándolas de forma que se puedan llevar a la práctica.

En cumplimiento del cometido que tiene asignado, el Departamento de Educación, Política Lingüística y Cultura ha convocado y resuelto anualmente diversas órdenes de subvención sectoriales. Así, mediante la Orden de 2 de mayo de 2013 (BOPV N 85/2013), acordó convocar la convocatoria correspondiente a 2013 por la que se regulaba la concesión de subvenciones para la promoción, difusión y/o normalización del euskera en la sociedad. El objeto de esta convocatoria era regular y convocar para el ejercicio 2013 la concesión de subvenciones a personas físicas o jurídicas privadas que desarrollan una labor de promoción, difusión y/o normalización del euskera en la sociedad (Convocatoria Euskalgintza) con una dotación presupuestaria de 979.200 euros.

\subsection{Galicia}

El artículo 5 del Estatuto de Autonomía de Galicia reza que la lengua propia de Galicia es el gallego y que el uso normal y oficial de los dos idiomas debe ser garantizado por los poderes públicos de Galicia. Además, la Ley de normalización lingüística establece que la Xunta debe contribuir a fomentar el gallego en los medios de comunicación. En este sentido, la Administración gallega subvenciona publicaciones periódicas escritas íntegramente en la lengua gallega y empresas periodísticas y de radiodifusión que aunque se editen en castellano utilizan el gallego en algún espacio. 
Colino, Alberto. Evolución de la financiación de los medios de comunicación en España. ¿Hacia un modelo más sostenible?

Así, la Administración gallega dispone de dos líneas de subvenciones:

- A las publicaciones periódicas escritas íntegramente en gallego.

- A las empresas periodísticas y de radiodifusión (editoras de prensa, agencias de noticias, emisoras de radio y portales de Internet) que editen espacios en castellano en los que se utilice, en mayor o menor medida, la lengua gallega.

De este modo, los subsidios a las publicaciones periódicas escritas íntegramente en gallego son una ayuda selectiva que examina una comisión formada por miembros de la Secretaría de Comunicación, junto con personal de la Secretaría General de Política Lingüística, de acuerdo con los criterios de uso regular del gallego normativo, así como de su tirada, difusión y periodicidad. Además, podrán optar a las ayudas a empresas periodísticas y de radiodifusión aquellas publicaciones (en papel o electrónicas) y emisoras de radio (se excluye la televisión) que difundan informaciones en las que tenga un especial protagonismo la lengua, la cultura y la identidad gallegas. Por ello, además de la difusión y la periodicidad del medio solicitante, también se utiliza como criterio el porcentaje de uso del gallego.

Además, estas ayudas económicas son compatibles con otras ayudas concedidas por otras Administraciones o entes públicos o privados nacionales o internacionales siempre que la acumulación de ayudas no supere el coste total de la actividad subvencionada y se respeten las condiciones establecidas en cada régimen de ayudas en la normativa nacional y comunitaria aplicable.

\subsection{Asturias}

En Asturias también se otorgan subvenciones a los medios. Por ejemplo, entre 2007 y 2011 se concedieron ayudas por un total de 1.750 .562 euros para, de nuevo, fomentar el uso del asturiano y el asturiano-gallego en los medios. La Nueva España es el periódico que mejor parado sale, recibiendo una ayuda de 310.224 euros, seguido de lejos por El Comercio y La Voz de Asturias.

\subsection{Andalucía}

En otros Gobiernos autonómicos, como el de Andalucía, es también tradición implicarse económicamente en el "progreso" de los medios de comunicación. Así, el Boletín Oficial de la Junta de Andalucía (BOJA) anunció hace un año la ayuda de 330.000 euros que la Consejería de Educación entregaría al diario El País.

El Gobierno de Andalucía reconoció en su momento que se trataba de una subvención excepcional a la que no pudieron optar otros medios. Además, se adjudicaron 69.369 euros a la Corporación de Medios de Andalucía para "contribuir a la difusión del diario Ideal".

Del mismo modo, la Junta de Andalucía aprobó mediante la Orden de la Consejera de la Presidencia a principios de año las bases reguladoras para recibir las subvenciones. El fin último sería, a falta de una lengua propia que promocionar, el fomento de la lectura de la prensa escrita en Andalucía. 
Colino, Alberto. Evolución de la financiación de los medios de comunicación en España. ¿Hacia un modelo más sostenible?

\section{EVOLUCIÓN RECIENTE DE LA FINANCIACIÓN DE LOS MEDIOS DE COMUNICACIÓN}

Esta sección analiza en primer lugar la composición de los ingresos de los medios de comunicación en España, centrándose para ello en el mercado de las telecomunicaciones. Así, en la Tabla 1 comenzamos ofreciendo una visión de la evolución de los ingresos de los operadores en los mercados nacionales de comunicaciones electrónicas y de servicios audiovisuales, prestando especial atención a la televisión y la radio.

Como se puede observar, de acuerdo con los datos ofrecidos por la Comisión del Mercado de las Telecomunicaciones (CMT), los ingresos publicitarios habían venido siendo la principal fuente de financiación de los Servicios audiovisuales a nivel nacional en la última década, hasta que en 2009 cayeron bruscamente por la entrada en vigor de la ya mencionada Ley 8/2009 que planteaba el proceso de cambio estructural del modelo de financiación de RTVE, mediante el cual se renunciaba definitiva e inmediatamente a los ingresos publicitarios y se pasaba a un sistema único de financiación basado en ingresos públicos.

Es por esto que este año marcó un cambio de tendencia que se ha visto culminado en los dos últimos años, 2011 y 2012, cuando los ingresos procedentes de subvenciones a los entes públicos han superado en importancia a los procedentes de la publicidad. Este cambio en la hegemonía de los ingresos provenientes de la publicidad es consecuencia inmediata del cambio acontecido en los últimos años en el sistema de financiación de los medios de comunicación, por lo que los analizaremos en detalle más adelante en este mismo apartado.

Figura 1.- Ingresos de Servicios Audiovisuales por concepto en 2003 y 2012 (Porcentaje)

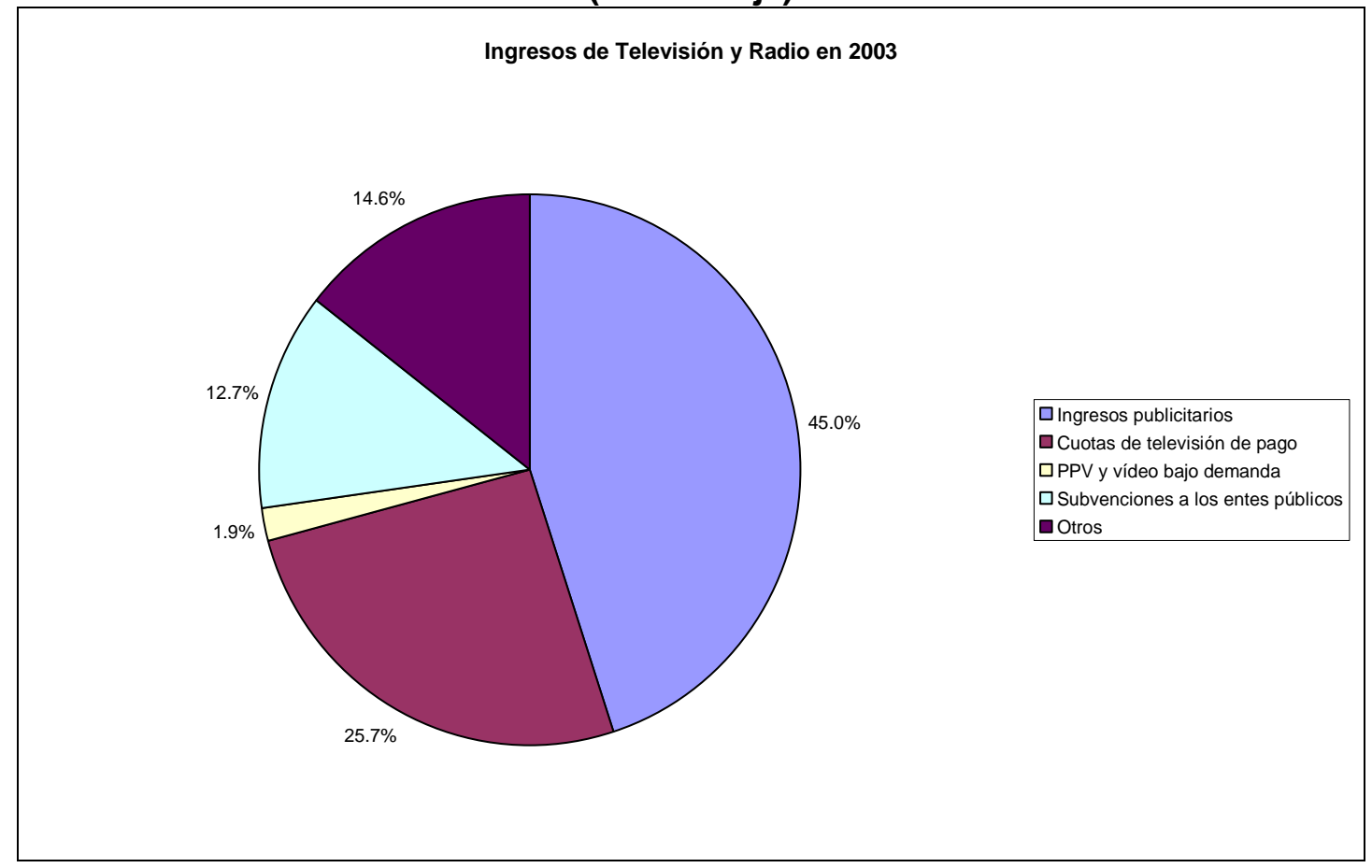


Colino, Alberto. Evolución de la financiación de los medios de comunicación en España. ¿Hacia un modelo más sostenible?

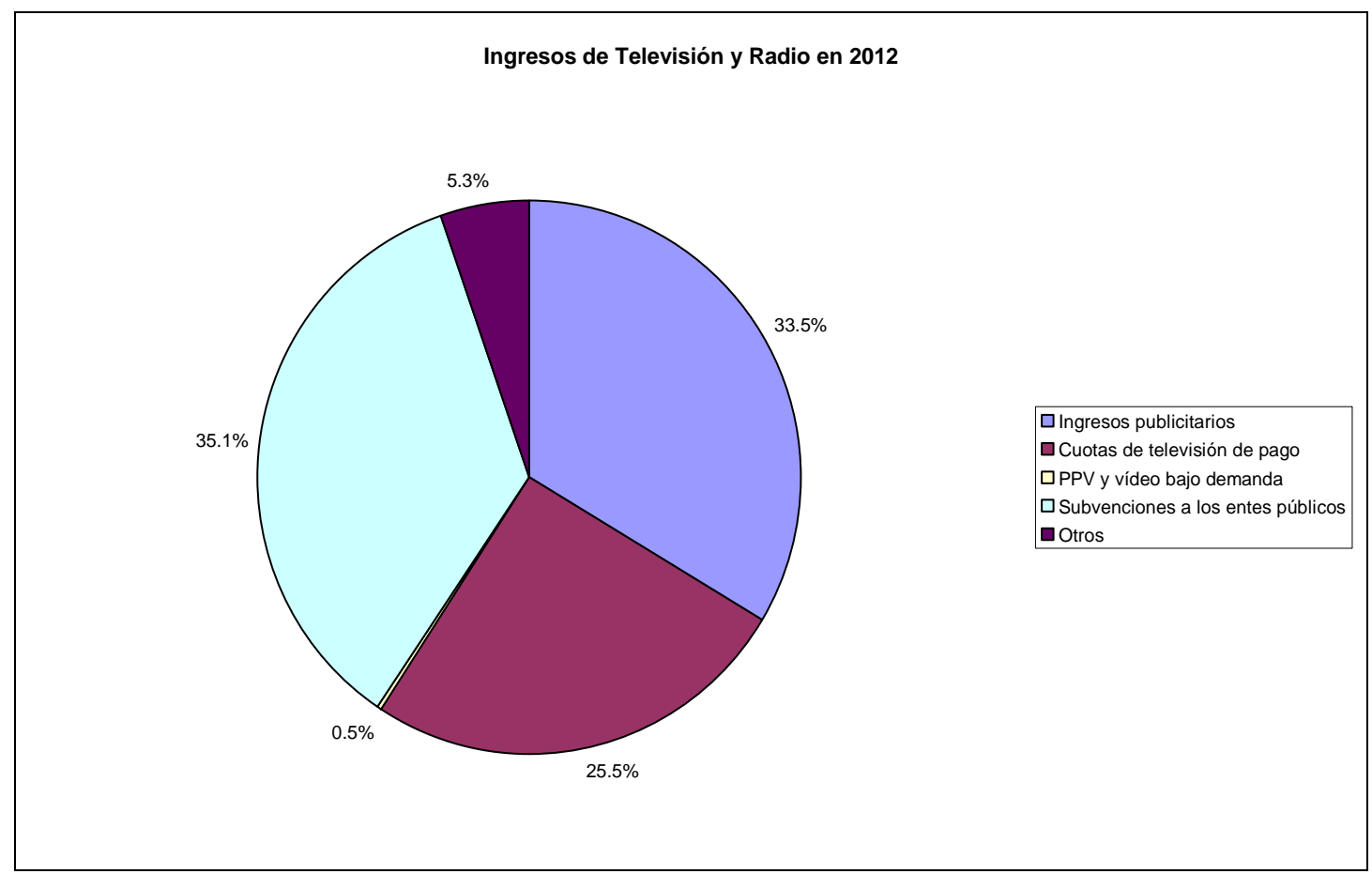

Fuente: Comisión del Mercado de las Telecomunicaciones (CMT)

De este modo, como se muestra en la Figura 1, mientras que en el año 2003 los ingresos publicitarios suponían el $45 \%$ de los ingresos de las televisiones y radios, las subvenciones otorgadas a los entes públicos representaban solo el $12,7 \%$ y ocupaban el tercer lugar entre las fuentes de financiación. Esta tendencia se invirtió y ya en 2011 los ingresos por subvenciones $(36,1 \%)$ se situaban por delante de los provenientes de la publicidad (36\%). La foto fija de 2012 muestra ese mismo patrón, con unos ingresos publicitarios que se habían reducido hasta el 33,5\% del total, mostrando la incapacidad de los operadores privados para capitalizar la disminución causada por la supresión de los ingresos que la Corporación RTVE dejó de percibir por su renuncia al mercado publicitario.

Respecto al resto de componentes del ingreso de las operadoras de televisión y radio españolas, como acabamos de comentar, encontramos en el año 2003 en segundo lugar por orden de importancia a los ingresos procedentes de las cuotas pagadas por los abonados de las televisiones de pago que suponían alrededor de un cuarto de los mismos (25,7\%). En 2012 mantenían su importancia como fuente de ingresos con una porcentaje del $25,5 \%$.

Ya con proporciones inferiores encontramos los conceptos de Otros -que incluye ingresos derivados de producciones propias, envío de SMS, Ilamadas de tarificación adicional, etcétera- con un porcentaje del 14,6\% en 2003 y del 5,3\% en 2012 y Pay Per View (PPV) y vídeo bajo demanda (1,9\% en el año 2003 y $0,5 \%$ en 2012).

En lo referente a la evolución temporal de los distintos conceptos, la Figura 2 nos muestra el importante avance experimentado por la partida de subvenciones, que pese a haber retrocedido más de un $13 \%$ en el último año, se anota un crecimiento medio para todo el periodo estudiado cercano al 17\%. De hecho, entre el comienzo y el final del periodo, este concepto casi se ha multiplicado por tres, pasando de los 
Colino, Alberto. Evolución de la financiación de los medios de comunicación en España. ¿Hacia un modelo más sostenible?

681 millones de euros que suponía en 2003 a tener un monto total de más de 2,000 millones en 2012.

Figura 2.- Ingresos de Servicios Audiovisuales por concepto (2003=100)

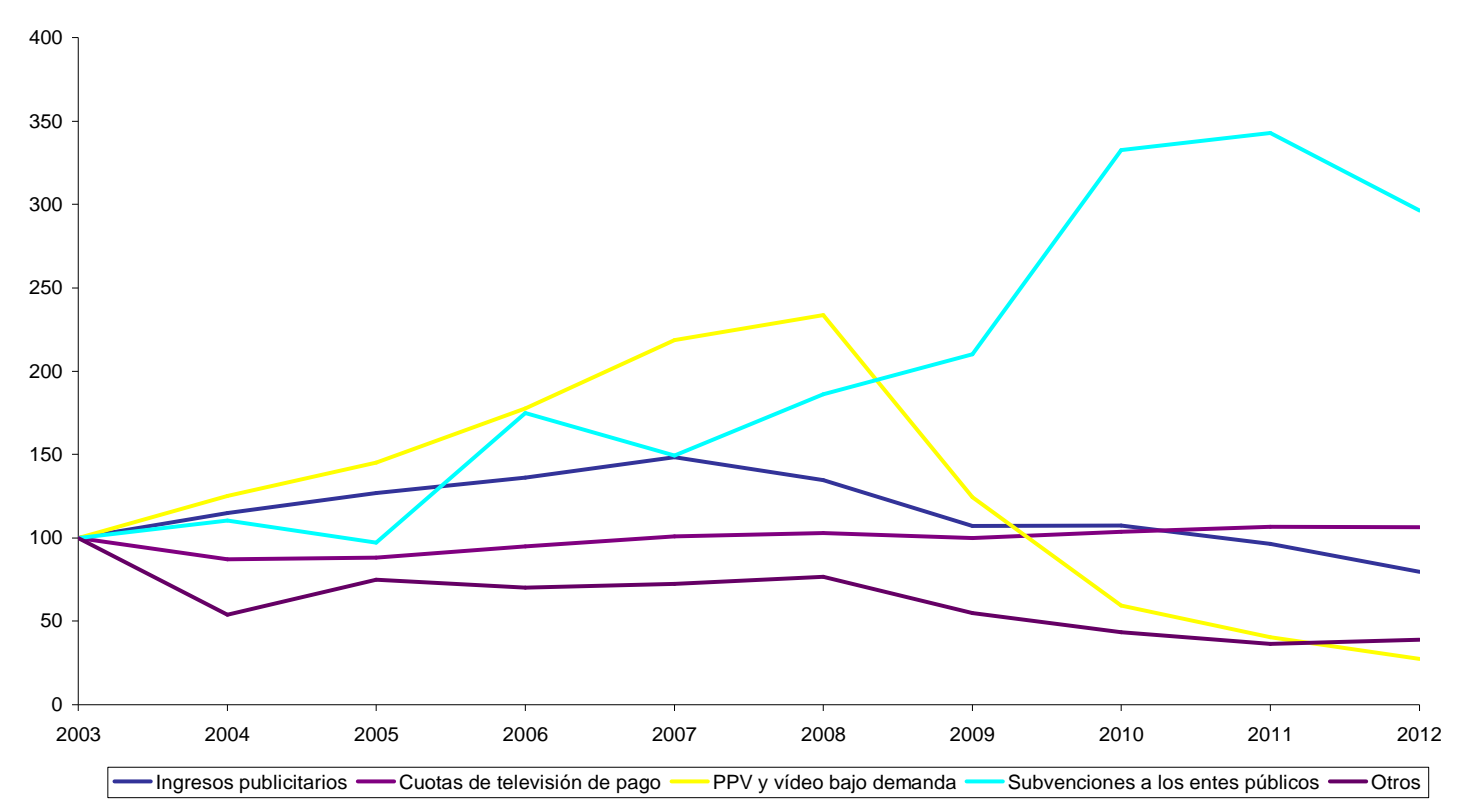

Fuente: Comisión del Mercado de las Telecomunicaciones (CMT)

Por supuesto, este crecimiento no tiene parangón en ninguno de los otros componentes del ingreso en el periodo 2003-2012 y como se puede observar, de hecho solo hubo otra partida que experimentara en media un crecimiento positivo, las cuotas de televisión de pago, que se apuntaron un avance inferior al 1\%, desde los 1,380 millones de euros en 2003 hasta los 1,468 de 2012.

Ahora bien, como ya se señalaba anteriormente, las trayectorias seguidas por cada uno de los componentes del gasto han sido muy dispares, por lo que resulta de interés proceder a analizarlas un poco más en detalle. Antes de proceder, es conveniente considerar la evolución seguida por todas ellas en su conjunto si observamos la penúltima fila de la Tabla 1. De este modo, podemos ver como los ingresos de los servicios audiovisuales en España vinieron aumentando hasta el año 2007 en que se desencadenó la crisis financiera mundial y posteriormente se estancaron en 2008 alrededor de los 6,800 millones de euros.

Lo que ocurrió en 2009, un desplome de más del $12 \%$ respecto al año anterior, devolviendo los niveles de ingresos a cifras propias de cuatro años atrás, fue el resultado de dos factores; por un lado, la reducción de los ingresos publicitarios en 665 millones de euros, un $20 \%$ menos que el año 2008, partida esta que ya se había contraído el año anterior un $9 \%$ y, por otro, la drástica reducción de los conceptos de PPV y vídeo bajo demanda en 113 millones de euros (-47\%) y Otros en 170 millones de euros $(-28 \%)$. 
Tabla 1.- Ingresos de Servicios Audiovisuales por concepto (2003-2012) Millones de euros y porcentaje

\begin{tabular}{|c|c|c|c|c|c|c|c|c|c|c|}
\hline Concepto & 2003 & 2004 & 2005 & 2006 & 2007 & 2008 & 2009 & 2010 & 2011 & 2012 \\
\hline \multirow[t]{2}{*}{$\begin{array}{l}\text { Ingresos } \\
\text { publicitarios }\end{array}$} & $2.413,66$ & $2.772,11$ & $3.066,82$ & $3.290,47$ & $3.582,48$ & $3.250,99$ & $2.585,00$ & $2.589,20$ & $2.328,07$ & $1.925,62$ \\
\hline & 45,0 & 52,5 & 54,0 & 50,4 & 52,8 & 48,0 & 43,4 & 38,7 & 36,0 & 33,5 \\
\hline \multirow[t]{2}{*}{$\begin{array}{l}\text { Cuotas de } \\
\text { televisión de pago }\end{array}$} & $1.379,86$ & $1.200,86$ & $1.216,41$ & $1.309,66$ & $1.393,69$ & $1.419,36$ & $1.377,46$ & $1.430,70$ & $1.471,32$ & $1.467,55$ \\
\hline & 25,7 & 22,8 & 21,4 & 20,1 & 20,5 & 20,9 & 23,2 & 21,4 & 22,8 & 25,5 \\
\hline \multirow[t]{2}{*}{$\begin{array}{l}\text { PPV y vídeo bajo } \\
\text { demanda }\end{array}$} & 104,17 & 130,26 & 151,07 & 184,91 & 227,70 & 243,42 & 129,51 & 61,89 & 42,09 & 28,38 \\
\hline & 1,9 & 2,5 & 2,7 & 2,8 & 3,4 & 3,6 & 2,2 & 0,9 & 0,7 & 0,5 \\
\hline \multirow[t]{2}{*}{$\begin{array}{l}\text { Subvenciones a los } \\
\text { entes públicos }\end{array}$} & 681,16 & 752,52 & 660,90 & $1.190,92$ & $1.017,70$ & $1.268,51$ & $1.430,47$ & $2.264,85$ & $2.334,55$ & $2.019,13$ \\
\hline & 12,7 & 14,3 & 11,6 & 18,3 & 15,0 & 18,7 & 24,0 & 33,9 & 36,1 & 35,1 \\
\hline \multirow[t]{2}{*}{ Otros } & 780,45 & 420,39 & 584,55 & 547,48 & 564,51 & 597,56 & 427,69 & 339,71 & 283,21 & 304,48 \\
\hline & 14,6 & 8,0 & 10,3 & 8,4 & 8,3 & 8,8 & 7,2 & 5,1 & 4,4 & 5,3 \\
\hline \multirow[t]{2}{*}{ Total } & $5.359,30$ & $5.276,14$ & $5.679,75$ & $6.523,44$ & $6.786,08$ & $6.779,84$ & $5.950,13$ & $6.686,35$ & $6.459,24$ & $5.745,16$ \\
\hline & 100,0 & 100,0 & 100,0 & 100,0 & 100,0 & 100,0 & 100,0 & 100,0 & 100,0 & 100,0 \\
\hline
\end{tabular}

Fuente: Comisión del Mercado de las Telecomunicaciones (CMT) 
Colino, Alberto. Evolución de la financiación de los medios de comunicación en España. ¿Hacia un modelo más sostenible?

El año 2010 resultó extremadamente positivo en términos de ingresos, ya que los mismos aumentaron desde los 6,000 millones de 2009 hasta alrededor de los 6,700 millones de 2010. Esta sorprendente recuperación de los ingresos en plena crisis económica tiene una explicación clara, la generosa contribución del Estado en forma de subvenciones. Recordemos que en agosto de 2009 se aprobó una nueva ley de financiación para RTVE que eliminó la publicidad. El modelo entró en vigor el 1 de enero de 2010 y precisamente es en ese año cuando se produjo un incremento exponencial en las subvenciones. De hecho, las ayudas públicas totales en 2009 se situaron en sólo 1.430,5 millones de euros; la factura aumentó 830 millones un año después -un aumento de más del $58 \%$.

De este modo, si excluimos las subvenciones, el sector de servicios audiovisuales en España facturó 4.422,6 millones de euros. Esta cifra supuso un descenso del $2,1 \%$ en la facturación debido a la reducción en la demanda de los servicios de pago por visión, mientras que los derivados de la publicidad y de las cuotas de abonados a la televisión de pago aumentaron ligeramente.

En este sentido, los abonados a la televisión de pago crecieron un $7,7 \%$ y sumaron casi los 4,6 millones.

Hasta la reforma, aproximadamente la mitad del dinero que recibía RTVE procedía de los Presupuestos Generales del Estado y el resto dependía de los ingresos publicitarios. Sin embargo, el nuevo modelo establece que los cuantiosos ingresos que se pierden por publicidad se compensan con tasas a las operadoras y a las televisiones privadas, así como entregando a la Corporación un porcentaje de la recaudación por el pago del espectro radioeléctrico. Es decir, más subvenciones para garantizar a la televisión pública una facturación anual de 1.200 millones.

En cuanto a las subvenciones percibidas por los operadores públicos crecieron de forma notable y alcanzaron los $2.264,9$ millones de euros, explicado en parte por el nuevo modelo de financiación de la Corporación. De esta cifra, 251,8 millones se destinaron al segmento de la radio y $2.013,1$ al de la televisión.

La perspectiva del tiempo permite al menos cuestionar el atrevimiento de renunciar a ingresos seguros procedentes de la publicidad en plena crisis económica. Eso sí, como mencionaremos a continuación, parece ser que las empresas privadas se han hecho con parte de los recursos liberados por la supresión de la publicidad en la Corporación y parece que están dispuestas a luchar para que no se revierta un modelo también cuestionado desde la Unión Europea.

En los años subsiguientes, 2011 y 2012, los ingresos totales del sector continuaron cayendo como consecuencia de la crisis económica y la consiguiente reducción en la inmensa mayoría de los conceptos. Resulta de especial interés el año 2011, en el que pese a la ampliación de la cantidad en forma de subvención del Estado $(3,1 \%)$ el conjunto del sector audiovisual vio reducidos sus ingresos en 226 millones de euros $(-3,4 \%)$ desde los 6,686 millones de 2010 a los 6,460 un año después. El año 2012 prolongó la 
Colino, Alberto. Evolución de la financiación de los medios de comunicación en España. ¿Hacia un modelo más sostenible?

tendencia a la baja de los ingresos con una caída de los mismos de más de 700 millones de euros, un 11\% menos que el año 2011.

Es de destacar que, como se puede observar por los datos presentados, pese al despilfarro que suponen las televisiones públicas esto no se ha traducido en recortes decididos de ese gasto durante los últimos años caracterizados por una intensa crisis económica. De este modo, aunque en 2012 se redujeron las subvenciones un $13,5 \%$ respecto a su cifra de 2011 , en este año se realizó un dispendio de 2.334,5 millones de euros por parte de las diferentes administraciones. Una cifra que superaba con creces los 2.264,9 millones del año anterior y casi duplicaba los $1.268,5$ millones desembolsados en 2008 , con la crisis económica dando sus primeros pasos.

A la vista de los datos, tampoco parece que las autonómicas hayan dado pasos decididos para corregir la situación. Así, la CMT relaciona las medidas de contención adoptadas por los gobiernos regionales, en apariencia sólo paliativas. Por ejemplo, el supervisor expone en el Informe Económico y Sectorial de 2011 que Castilla-La Mancha cerró su segundo canal y que otros operadores como la Corporación Extremeña, la Corporación Aragonesa, la Radio Televisión del Principado de Asturias o la Radiotelevisió Valenciana prescindieron de la emisión por satélite de sus canales. Sólo ayuntamientos grandes como el de Madrid o Mallorca "optaron por cerrar sus televisiones municipales como medida de recorte de gastos presupuestarios".

A continuación, centramos nuestra atención en la senda seguida por los ingresos en publicidad, como la principal fuente de financiación de los medios de comunicación públicos en España hasta la entrada en vigor de la ley de financiación para la Corporación de RTVE que eliminó la publicidad. Recordemos que la citada ley establecía que la supresión de los ingresos procedentes de la publicidad conllevaba la implementación de otras medidas destinadas a garantizar legalmente que la Corporación RTVE fuera compensada suficientemente con los ingresos públicos que le permitieran seguir prestando el servicio público encomendado en la ley y el mandatomarco, pero sin dejar de cumplir con el principio de equilibrio presupuestario.

Claramente, la entrada en vigor de la Ley 8/2009 hubo de suponer un cambio acusado en la evolución seguida por los ingresos publicitarios del sector en su conjunto y más concretamente en los percibidos por los operadores públicos que debieron de verse drásticamente reducidos. Para estudiar su evolución, en la Tabla 2 se presentan las cifras de ingresos publicitarios en el sector audiovisual desagregadas por operadores desde comienzos de los años 2000 hasta la actualidad. Como se puede observar, podemos distinguir dos etapas claramente diferenciadas en cuanto a la evolución de los ingresos por publicidad. 
Tabla 2.- Ingresos publicitarios de Televisión y Radio por tipo de operador (2000-2012) Millones de euros

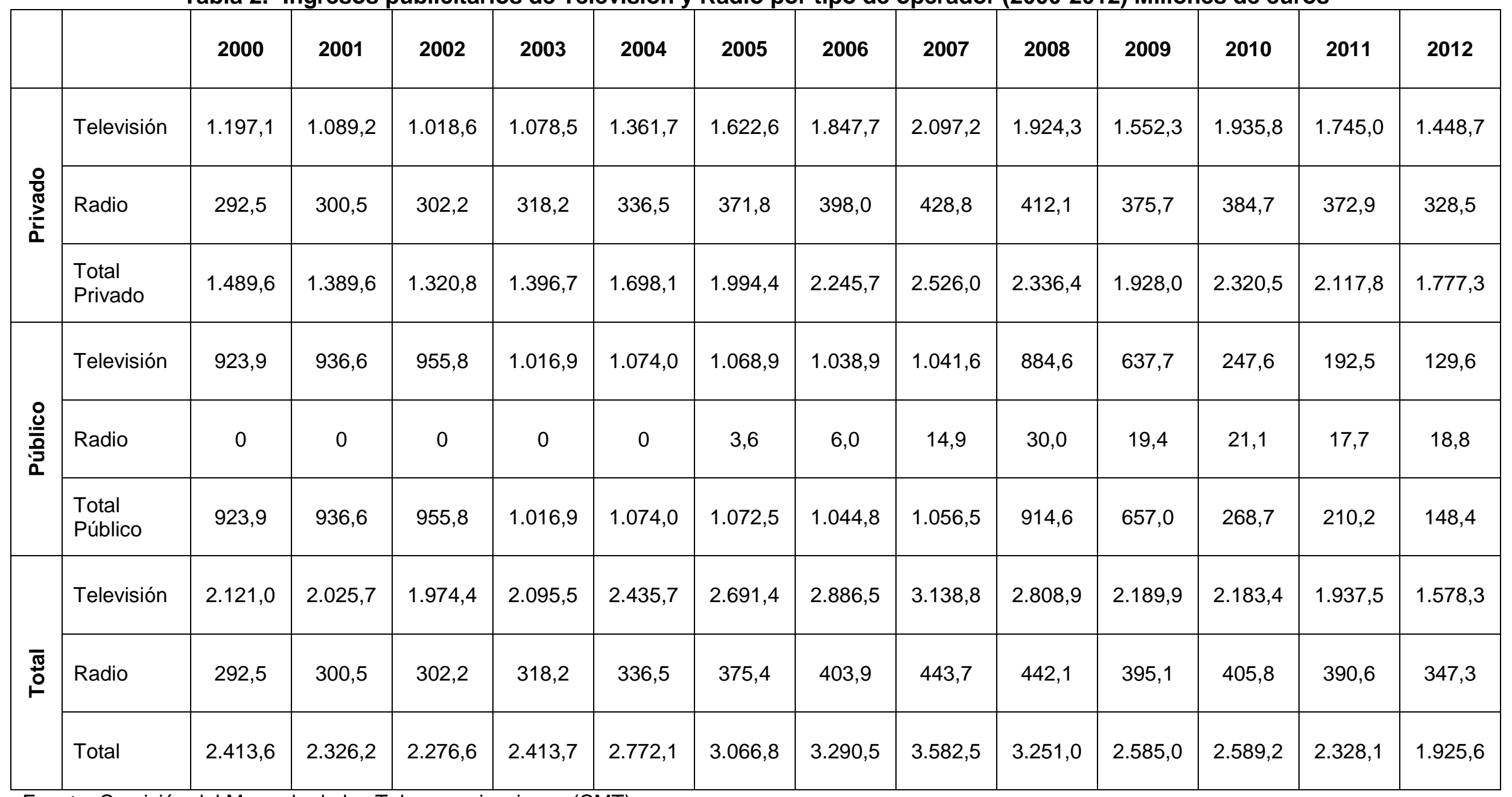

Fuente: Comisión del Mercado de las Telecomunicaciones (CMT) 
Colino, Alberto. Evolución de la financiación de los medios de comunicación en España. ¿Hacia un modelo más sostenible?

En una primera etapa, cuyo punto máximo lo marca el año 2007 y el inicio de la crisis financiera internacional, la serie se caracteriza -si exceptuamos las leves caídas en los dos primeros años de la serie- por un crecimiento sostenido de los ingresos publicitarios en su conjunto. Así, la cuantía alcanzada por los ingresos publicitarios en 2007 fue de 3.582,5 millones de euros, de los cuales 2.526 millones correspondían a los operadores privados y $1.056,5$ a operadores públicos.

El mismo patrón puede observarse si entramos a analizar en detalle tanto a los operadores privados como a los públicos, si bien los incrementos experimentados por los ingresos publicitarios de los últimos siempre fueron mucho más moderados -su máximo alcanzado en 2003 con un crecimiento del $6,3 \%$. De hecho, este año marca el punto de inflexión en cuanto al crecimiento en la proporción de los ingresos publicitarios acaparados por los operadores públicos -el $42,1 \%$ frente al $57,9 \%$ de los operadores en manos privadas- que había venido siendo constante desde el inicio de los años 2000. A partir de este año, la participación de los operadores privados en los ingresos publicitarios ha aumentado paulatinamente hasta alcanzar una cuota del 92,3\% en 2012.

Respecto a los operadores privados, esta primera etapa de continuada expansión de los ingresos por publicidad se anotó su mayor crecimiento en el año 2004, con un aumento del 21,6\%. Este incremento, junto con el experimentado por los ingresos de los operadores públicos $(5,6 \%)$ conllevó una ampliación de los ingresos publicitarios del sector audiovisual de casi el 15\% -la mayor de toda la serie analizada- desde los 2.414 millones de euros de 2003 hasta los 2.772 millones obtenidos en 2004.

Los últimos tres años de esta primera etapa expansiva, entre 2005 y 2007, también vieron aumentar los ingresos publicitarios del sector, pero a ritmos más moderados. Así, el promedio de crecimiento se situó en el entorno del 9\% anual para el sector en su conjunto $-14,2 \%$ de crecimiento para los operadores privados, que fueron los que tiraron del sector en este periodo y $-0,5 \%$ para los públicos que se estancaron e incluso retrocedieron- desde los 3.067 millones de euros de 2005 hasta alcanzar los ya mencionados 3.582,5 en 2007.

La segunda etapa que puede distinguirse en cuanto a la evolución de los ingresos publicitarios del sector audiovisual comenzó en el año 2008 y ha estado marcada por la intensa crisis económica y la consiguiente caída de los ingresos en publicidad. Así, entre 2008 y 2012, los ingresos publicitarios del sector cayeron en promedio anual un 11,4\%, siendo el más acusado el desmoronamiento de los operadores públicos, con un descenso medio del $30,4 \%$.

Ya en el año 2008 y a la espera de la firma del primer contrato-programa de la Corporación, fueron las Leyes de Presupuestos Generales del Estado para 2008 y para 2009 las que incluyeron sendas reducciones publicitarias de un minuto, situándose la misma en el tope máximo de emisión publicitaria para la Corporación en diez minutos por hora de reloj. Correlativamente, y en aras del mantenimiento del equilibrio presupuestario, fue preciso compensar el consecuente descenso de ingresos con fondos públicos -como se puede 
Colino, Alberto. Evolución de la financiación de los medios de comunicación en España. ¿Hacia un modelo más sostenible?

observar en la Tabla 1 en los años 2008 y 2009 las subvenciones aumentaron un 24,6 y un $12,8 \%$ respectivamente.

Como indica la ley, "la reducción de la publicidad en la Corporación RTVE tiene como objetivo garantizar la estabilidad en sus ingresos y, en consecuencia, favorecer el equilibrio presupuestario evitando riesgos para el mantenimiento de la prestación del servicio público encomendado. Este objetivo permite asimismo reforzar la independencia del servicio público frente a consideraciones de mercado que pudieran afectar a la prestación del servicio encomendado y facilita la determinación de la compensación a RTVE para poder cubrirlo." Así, en 2008 y 2009, los ingresos por publicidad de los operadores públicos cayeron en casi 400 millones de euros desde los 1.056,5 millones del año 2007 hasta los 657 millones dos años después (casi un 61\%).

Pero en este periodo de dos años no solo se vieron afectados negativamente los ingresos publicitarios de los operadores públicos, sino que la incipiente crisis económica en España retrajo también los ingresos por este concepto de los operadores privados. Precisamente, los datos ofrecidos por la CMT muestran que los ingresos publicitarios de los operadores privados entre 2007 y 2009 se redujeron en aproximadamente 600 millones de euros (un 31\%).

El año 2010 supuso para los operadores privados un cambio radical respecto a los años precedentes y así las cadenas privadas de radio y televisión aumentaron un $20,4 \%$ sus ingresos publicitarios. Es decir, en un solo año las cadenas privadas aumentaron un $20,4 \%$ sus ingresos publicitarios debido a la redistribución de la publicidad entre los operadores por el fin de la emisión de anuncios por parte de la Corporación de Radio Televisión Española.

Por lo tanto, la entrada en vigor del nuevo modelo de financiación de CRTVE, que dejó de emitir anuncios, provocó una reasignación de los ingresos de publicidad. Así, las televisiones privadas aumentaron en 2010 un 24,7\% sus ingresos publicitarios, en comparación con el año anterior; en concreto, de los 1.552 millones de euros recaudados por estos operadores en 2009, se pasó a 1.935,8 millones de euros. En términos absolutos supuso un avance de 383,5 millones de euros. Del mismo modo, las radios privadas vieron aumentar sus ingresos publicitarios desde los 375,7 millones de euros de 2009 a los 784,7 millones de euros un año después.

El incremento en la facturación por publicidad de las privadas contrastó con la disminución de los ingresos publicitarios de las operadoras públicas, que los redujeron en un 59,1\%, hasta los 247,6 millones de euros. En términos absolutos supuso un retroceso de 390 millones de euros.

Como se puede observar en la Tabla 2, el año 2011 no fue diferente para las operadoras públicas, que vieron reducirse sus ingresos publicitarios en 58,5 millones de euros adicionales (un 21,8\%) hasta los 210 millones de euros. Precisamente, en este año y a diferencia del anterior, en el que solo habían caído los ingresos publicitarios de las cadenas públicas de televisión, cayeron tanto los ingresos de cadenas de televisión $(-22,2 \%)$ como de radio $(-16,2 \%)$. 
Colino, Alberto. Evolución de la financiación de los medios de comunicación en España. ¿Hacia un modelo más sostenible?

Sin embargo, este año si supuso una novedad en la dinámica experimentada por los ingresos de los operadores privados de radio y televisión, ya que no continuaron aumentando sus ingresos publicitarios como en el año 2010, sino que los redujeron de manera sustancial $(-8,7 \%)$. De hecho, en este año los datos de la CMT constatan el duopolio publicitario hacia el que se encamina el sector audiovisual, con Mediaset y Antena 3 como operadores de referencia. Así, entre ambos controlan tres cuartas partes del mercado. Como se señala en el Informe Económico y Sectorial de 2011 "De un análisis de la concentración de la inversión publicitaria en el medio televisivo, se deriva que, en conjunto, Mediaset España (que cuenta actualmente con siete canales de programación), que gestiona su negocio publicitario a través de Publisespaña, y Antena 3 (con cuatro canales), que canaliza esta actividad desde Atres Advertising, captaron el $75,3 \%$ del total de los ingresos publicitarios."

Finalmente, en la última columna de la Tabla 2 encontramos los datos sobre ingresos publicitarios correspondientes a 2012. Como se puede ver, el año pasado resultó nuevamente negativo en términos de ingresos, tanto para los operadores privados como para los públicos, que tuvieron como resultado una reducción en los ingresos totales del sector de un 17,3\% desde los 2.328 miles de millones de 2011 a los 1.925,6 de 2012.

De este modo, los ingresos publicitarios de las televisiones públicas cayeron un $32,7 \%$ el año pasado, hasta sumar 129,61 millones de euros, mientras que las de las privadas lo hicieron un 17\%, hasta los 1.448,72 millones de euros. Así, la crisis económica, que está reduciendo los ingresos publicitarios de las cadenas, afectó el año pasado especialmente a las televisiones autonómicas y locales públicas, que son las que todavía emiten publicidad, ya que como hemos comentado con anterioridad, CRTVE dejó de hacerlo a finales de 2009 con la entrada en vigor del nuevo modelo de financiación aprobado por el anterior Gobierno.

Como señala CMT en su Informe del cuarto trimestre de 2012, las televisiones de pago reaccionaron mejor a la crisis el año pasado, y vieron como sus ingresos -que obtienen a través de las cuotas que pagan sus clientesaumentaron un $1,4 \%$, hasta los $1.467,55$ millones de euros. Sin embargo, los ingresos por servicios de pago bajo demanda cayeron un $40 \%$, hasta los 28,38 millones de euros.

Análogamente, por tipo de tecnología, la televisión por satélite vio incrementada sus ganancias un $7,6 \%$ hasta los 1.060 millones de euros, al igual que también crecieron la televisión a través de Internet $(247,61$ millones de euros, un 10,38\% más) y la televisión móvil (15,57 millones de euros, un $12,9 \%$ más). Mientras, los ingresos de la televisión de cable y televisión por terrestre cayeron un $15,6 \%$ y un $21,4 \%$, respectivamente.

Respecto a las radios, las emisoras privadas vieron reducidos sus ingresos publicitarios el año pasado un 12\%, desde los 372,9 millones de euros de 2011 hasta los 328,5 millones de euros del año pasado. 
Colino, Alberto. Evolución de la financiación de los medios de comunicación en España. ¿Hacia un modelo más sostenible?

Para analizar en profundidad el avance de los recursos destinados a la publicidad en los medios de comunicación españoles, resulta interesante ampliar la información dada por la CMT con los datos ofrecidos por InfoAdex en su estudio anual sobre la inversión publicitaria en España, que se encarga de ofrecer la inversión real estimada obtenida por cada soporte. ${ }^{2}$

De acuerdo a la información y los datos ofrecidos en el último informe publicado en 2013, se puede observar que la inversión en publicidad viene cayendo desde el comienzo de la crisis económica, y que solo se recuperó ligeramente en 2010 cuando la misma dio un respiro. Así, según los datos reportados por InfoAdex, entre 2007-2012 la inversión en publicidad para el conjunto de los medios de comunicación nacionales se redujo desde los 16.121 millones de euros hasta los 10.859 millones de euros. Es decir, desde el principio de la crisis, la inversión en publicidad se redujo en casi 6.000 millones de euros, o lo que es lo mismo, un $32,6 \%$.

En términos anuales, el retroceso medio de la cifra total correspondiente a la inversión en publicidad se situó en el $-7,4 \%$. De hecho, como se puede ver en la Tabla 3, extraída de este mismo informe, el año en que esta se contrajo más es el año 2009, donde la inversión publicitaria se redujo hasta los 12.709 millones de euros -un $14,8 \%$ menos que en 2008. Con una caída en medios convencionales del $20,7 \%$ y en los no convencionales del $9,4 \%$.

Respecto a la inversión en medios audiovisuales, al igual que mostraban los datos correspondientes a los ingresos publicitarios de la CMT, el año 2009 también fue el de contracción más intensa de la inversión en publicidad, con un descenso de más de 800 millones de euros, desde los 3.724,3 millones de euros de 2008 a los casi 3.000 de 2009, alrededor de un $21,7 \%$ menos de la cifra desembolsada el año anterior. De esta cantidad, una reducción de más de 700 millones de euros correspondió a las televisiones $(-22,9 \%)$ y alrededor de 100 millones de euros a las radios $(-16,3 \%)$.

A excepción de la publicidad en Internet, que ha aumentado su inversión en casi 400 millones de euros desde 2007, el resto de medios audiovisuales también ha visto disminuir drásticamente la inversión en publicidad desde el comienzo de la crisis. Así, el cine pasó de los 38,4 millones de euros desembolsados en 2007 a los 22,5 millones de euros de 2012, una reducción del $41,4 \%$-si bien es cierto que experimentó dos años positivos con aumentos de la inversión en 2010 y 2011 - y los exteriores (carteleras, lonas, luminosos, etcétera) sufrieron un descenso del $42,6 \%$ y pasaron de una inversión de 568 millones de euros a 326,3 millones.

\footnotetext{
${ }^{2}$ Como puede leerse en su página web: "InfoAdex es el referente en el control de la actividad publicitaria en España, realizando un seguimiento exhaustivo y diario de la misma y proporcionando información sobre inversiones, inserciones, ocupación y creatividades, bien a través de sus herramientas InfoXXI y Mosaico2, bien mediante la producción de estudios, informes y análisis ad hoc.”
} 
Colino, Alberto. Evolución de la financiación de los medios de comunicación en España. ¿Hacia un modelo más sostenible?

Tabla 3.- Inversión real estimada en publicidad (2007-2012) Todos los medios (Millones de euros)

\begin{tabular}{|c|c|c|c|c|c|c|c|c|}
\hline \multicolumn{2}{|c|}{ Medios Comvencionales } & \multicolumn{2}{|c|}{$2012 \% 12 / 11$} & \multirow{2}{*}{$\begin{array}{l}2011 \\
25,8\end{array}$} & \multirow{2}{*}{$\begin{array}{r}2010 \\
24,4 \\
\end{array}$} & \multirow{2}{*}{$\begin{array}{r}2009 \\
15,4 \\
\end{array}$} & \multirow{2}{*}{$\begin{array}{r}2008 \\
21,0\end{array}$} & \multirow{2}{*}{$\begin{array}{r}2007 \\
38,4 \\
\end{array}$} \\
\hline Cine & Cine & 22,5 & $-12,7$ & & & & & \\
\hline Dianios & Diarios & 766,3 & $-20,8$ & 967,0 & $1.124,4$ & 1. 174,1 & $1.507,9$ & $1.894,4$ \\
\hline Dominicales & Dominicales & 52,0 & $-22,5$ & 67,1 & 72,2 & 68,9 & 103,9 & 133,5 \\
\hline \multirow[t]{8}{*}{ Exteriax } & Cateleras & 522 & $-11,9$ & 59,2 & 65,1 & 69,1 & 88.8 & 100,4 \\
\hline & Lonas & 12,1 & -4.5 & 12,7 & 14.2 & 19,6 & 28,0 & 31,9 \\
\hline & Luminosos & 10,9 & -19.5 & 13,5 & 15,0 & 16,7 & 17,9 & 19,5 \\
\hline & Mobliano (extencr + interior + cabinas ) & 155,6 & $-15,5$ & 184,1 & 198,1 & 182,5 & 233,9 & 255,8 \\
\hline & Monopostes: & 18,1 & $-10,1$ & 20,1 & 21,9 & 232 & 30,5 & 32,1 \\
\hline & Transporte & 70,7 & $-20,1$ & 88,5 & 88,2 & 80.2 & 105,9 & 112,3 \\
\hline & Otros & 6.8 & $-59,2$ & 16,7 & 18,3 & 10,1 & 13,3 & 16,1 \\
\hline & Total Exterior & 326,3 & $-17,3$ & 394,8 & 420,8 & 401,4 & 518,3 & 568,0 \\
\hline \multirow[t]{3}{*}{ Intemet $\left({ }^{*}\right\rangle$} & Enlaces patrocinados & 462,5 & 0,6 & 459,9 & 417.2 & 366,4 & 324.4 & 237,7 \\
\hline & Fomatos gráficos (t*) & 418,0 & -4.9 & 439,3 & 381,7 & 297.7 & 285,6 & 244,7 \\
\hline & Total Internet & 880,5 & $-2,1$ & 899,2 & 798,8 & 654,1 & 610.0 & 482,4 \\
\hline Rado & Radio & 453,5 & $-13,6$ & 524,9 & 548,5 & 537,3 & 641,9 & 678,1 \\
\hline \multirow[t]{3}{*}{ Revistas } & Inform. genera., femeninas, .... (*) & 183,1 & $-14,3$ & 213,6 & 218.8 & 212,8 & 326,5 & 385,6 \\
\hline & Otras & 130,6 & $-22,1$ & 167.5 & $1 \pi 9,0$ & 189,1 & 290,9 & 336,2 \\
\hline & Total Revistas & 313,7 & $-17,7$ & 381,1 & 397.8 & 401,9 & 617,3 & 721,8 \\
\hline \multirow[t]{6}{*}{ Television } & Canales de pago & 43,1 & $-2 B, A$ & 60,2 & 65,0 & 50,0 & 56,1 & 60,1 \\
\hline & TV. autondmicas & 126,8 & $-36,0$ & 198,0 & 272,6 & 237.7 & 319,6 & 354,7 \\
\hline & TV. locdes & 1,5 & $-25,0$ & 2,0 & 5,5 & 9,1 & 37.9 & 50,9 \\
\hline & TV. nacionales en ablerto & $1.643,9$ & $-16,8$ & $1.977,0$ & 2128,8 & $2.081,1$ & 2.068 .8 & $3.002,9$ \\
\hline & Total Televisión & $1.815,3$ & $-18,9$ & $2.237,2$ & 2471,9 & $2.377,8$ & $3.082,4$ & $3.468,6$ \\
\hline & Subtotal medios Convencionales (7) & $4.630,0$ & $-15,8$ & $5,497,1$ & $5.858,8$ & $5.630,9$ & $7,102,8$ & $7.985,1$ \\
\hline
\end{tabular}

\begin{tabular}{|c|c|c|c|c|c|c|c|}
\hline Medios No Comvencionales & 2012 & \%12/11 & 2011 & 2010 & 2009 & 2008 & 2007 \\
\hline Actos de patroc., mecenaz, mark. social y RSC & 397,7 & $-18,3$ & 486,8 & 537,3 & 500,3 & 569.5 & 495,1 \\
\hline Actos de patrocinio deportivo & 335,0 & $-20,4$ & 420,9 & 465,6 & 436,3 & 457.6 & 623,4 \\
\hline Animacide purto de venta & 70,9 & 3.2 & 68,7 & $e 2,1$ & 64,9 & 67.5 & 69.9 \\
\hline Anuarios, guias y directoricos & 156,3 & $-8,8$ & 171,4 & 387,8 & 485,9 & 609,9 & 638,6 \\
\hline Burzonedollolletos & 641,6 & $-10,6$ & 717,7 & 791,3 & 832,9 & 852,5 & 823,6 \\
\hline Catílogos & 49,3 & $-11,3$ & 55,6 & 112,5 & 120,0 & 144,1 & 193,7 \\
\hline Ferias y exposiciones & 64,2 & -11.0 & 72,2 & 86,1 & 80,8 & 109,0 & 200,7 \\
\hline Juegos promocionales & 27.9 & $-9,5$ & 30,9 & 39,3 & 44.7 & 50,3 & 55.9 \\
\hline Mailing personalizado & $1.881,6$ & $-1,7$ & $1.914,1$ & $1,971,3$ & 1.927 .0 & $1.976,4$ & $1.939,5$ \\
\hline Maketing mbivil (exclubido intemet) & 30,2 & -17.5 & 36,6 & 22,0 & 20,7 & 19,1 & 11,7 \\
\hline Maketina telefbnico & $1.157,7$ & 1.5 & $1,140,6$ & $1.103,1$ & $1.121,0$ & $1.100,6$ & $1.058,6$ \\
\hline PLV., merchandising, seflalizacion'y rótubs & 1285,3 & 0,7 & 1276,3 & $1.263,7$ & 1. 197.8 & $1.548,8$ & $1.538,0$ \\
\hline Public. de empresas: revistas, boletines, memorias & 22,1 & $-2,9$ & 227 & 25,3 & 23,7 & 32,5 & 53,3 \\
\hline Regalos publicitarios & 80,1 & $-29,4$ & 113,5 & 125,2 & 175,6 & 227,0 & 388,0 \\
\hline Tarietas de fidelizacion & 28,9 & 3.1 & 28,0 & 41,8 & 46,4 & 48.1 & 45,9 \\
\hline Subtotal Medios No Convencionales & $6.228,8$ & $-5,0$ & 6.555 , & $7.034,3$ & $7.078,1$ & $7.812,9$ & $8.136,1$ \\
\hline Gran total $\mathrm{Cl}$ & $10.858,8$ & $-9,9$ & $12.053,0$ & 12893,1 & $12,709,0$ & $14.915,7$ & $16.121,3$ \\
\hline
\end{tabular}

En cuanto al resto de medios escritos, tampoco se han librado de ver reducidas las cantidades invertidas en publicidad de manera radical. Así, en términos absolutos, los diarios han sido el medio más afectado por la crisis, ya que han reducido sus cuantías de manera abrupta $(-1.128,1$ millones de euros en cinco años), lo que ha supuesto un descenso del $59,6 \%$-en este caso no hubo recuperación en el año 2010-, los dominicales han visto disminuir la inversión en un $61,1 \%$ y la inversión en publicidad en las revistas ha caído en más de 400 millones de euros.

Papeles de Europa

Vol. 26, Núm. 1 (2013): 46-69 http://dx.doi.org/10.5209/rev_PADE.2013.n26.42801 
Colino, Alberto. Evolución de la financiación de los medios de comunicación en España. ¿Hacia un modelo más sostenible?

Por años, como ya se ha comentado, 2009 fue el que soportó la mayor parte del ajuste, pero es también de señalar el último año de la serie en el que se ha vuelto a producir un importante descenso de la inversión en publicidad en los medios de comunicación en España. Como señala el informe InfoAdex 2013, de nuevo, de manera global, la inversión publicitaria sufre un acusado descenso con respecto a los datos de 2011, con una bajada del 9,9\% para el total de medios. Así, la inversión en medios convencionales cayó un 15,8\% y la de los no convencionales un $5 \%$.

Dentro de los medios convencionales, si bien la inversión en televisión descendió un 18,9\% y en radio un 17,7\% de 2011 a 2012, fueron los medios impresos (diarios, revistas y suplementos) los que sufrieron una caída más acusada (20\%).

Además, en este último año se pueden destacar dos aspectos con respecto al reparto de la inversión. Por un lado, por primera vez en la cifra total anual el medio Internet superó a los diarios (16,6\%), colocándose en segunda posición en el ranking de inversión publicitaria con un 19\%, tras la televisión (39,2\%).

Por otro lado, todos los medios protagonizan una caída en su inversión publicitaria, incluido el medio Internet. Si bien la caída en la inversión en medios digitales fue de apenas un 2,1\% entre 2011 y 2012, como hemos señalado anteriormente, es la primera vez que sufre un descenso interanual.

\section{CONCLUSIONES}

El modelo de financiación de los medios de comunicación en España ha estado caracterizado por las abundantes inyecciones de dinero público destinado a mantener con vida artificialmente, viejos o nuevos medios, con la excusa de garantizar la disposición de un número suficiente de medios plurales al alcance de los ciudadanos. De hecho, en determinadas zonas de España esas ayudas han fluido de forma constante.

Este modelo mixto de financiación de los medios de comunicación ha sufrido importantes cambios en los últimos años, pero estos no han ido encaminados a reducir el despilfarro de recursos públicos. Así, en estos tiempos duros para el sector, se han demandado más subvenciones para el periodismo y esto ha conllevado una reducción en la contribución de los ingresos publicitarios en los medios de comunicación públicos y un aumento en la parte correspondiente a las subvenciones y otro tipo de ayudas públicas.

Por lo tanto, la tendencia seguida es hacia un sistema de financiación en el cual la garantía de la financiación es a costa de aumentar las aportaciones del Estado. Simultáneamente, aquellos que resultan beneficiados por esta decisión deben también soportar, en parte, esa carga económica. Así, siguiendo una fórmula utilizada por otros países de nuestro entorno, se ha establecido la imposición de una aportación razonable a las operadoras privadas para la financiación de la televisión pública. 
Colino, Alberto. Evolución de la financiación de los medios de comunicación en España. ¿Hacia un modelo más sostenible?

Estos cambios, enmarcados en el contexto actual de crisis económica, en el que las partidas destinadas a publicidad por parte de las compañías de todos los sectores se han reducido de forma drástica, cuando no se han eliminado de forma absoluta, han planteado la cuestión sobre la conveniencia de prescindir de la publicidad como medio de financiación. Más aún, no es de extrañar que incluso se haya ponderado la posibilidad de recuperar parte de la publicidad en la televisión pública para aligerar la carga en subvenciones.

A la luz de los datos, el goteo de recursos públicos continúa, no solo en la forma predominante de subvenciones, sino también a través de millonarias campañas de publicidad institucional o suscripciones masivas a medios de comunicación por parte de las Administraciones. Sin embargo, antes o después habrá que afrontar recortes en las arcas públicas, y estos afectarán a estas partidas. De hecho, en algunos casos esto ya ha ocurrido y ha supuesto el fin de determinados medios de comunicación que se mantenían en pie prácticamente tan sólo por el dinero entregado por las autoridades.

Además, esta no es la vía para garantizar medios de comunicación saneados e independientes, ya que de este modo dependen en exceso de las ayudas otorgadas por el sector público -detraídas de los ciudadanos a través de impuestos- y esto les impide ser críticos con el poder que los financia. De este modo, creemos en que los medios de comunicación de carácter público tienen la necesidad de continuar siendo un competidor de alto nivel y hacer contenidos de calidad, pero que es necesario mejorar los canales de financiación privados y no diseñar nuevos impuestos para financiar los medios de comunicación públicos. 
Colino, Alberto. Evolución de la financiación de los medios de comunicación en España. ¿Hacia un modelo más sostenible?

\section{REFERENCIAS}

Blasco Gil, J. J. (2008): "Las ayudas públicas a la prensa de las Comunidades Autónomas españolas en 2007: tipología, cuantía de las subvenciones y sistemas de adjudicación", Telos: Cuadernos de Comunicación e Innovación, no 75, pp. 95-103.

Comisión del Mercado de las Telecomunicaciones (2011): Informe Económico y Sectorial.

De la Quintana, A. y Oliva, C. (2012): "Subvenciones a la prensa en España: sinergias políticas y empresariales en Andalucía, Cataluña, Galicia y País Vasco", en Miguel Hernández Communication Journal, no 3, pp. 101-120.

Fernández Alonso, I., y Blasco Gil, J. J. (2006): "Press Subventions in Europe in 2006. Categories, Funding Provided and Assignation Systems", Press Subsidies in Europe: Proceedings of the Symposium Press Subsidies in Europe, Barcelona, Vol. 19, pp. 65-67.

Fernández Alonso, I., y Blasco Gil, J. J. (2008): "Las ayudas a la prensa en Europa en 2007: Los casos de Austria, Finlandia, Francia, Noruega y Suecia", Telos: Cuadernos de comunicación e innovación, no 75, pp. 85-94.

Fernández Alonso, I. \& Santana, F. (2000): Estado y medios de comunicación en la España democrática. Madrid: Alianza.

Humphreys, P. (2008): "Subvenciones a la prensa en Europa: una visión histórica”, Telos: Cuadernos de comunicación e innovación, ํㅡ7, pp. 7184.

InfoAdex (2013): Estudio InfoAdex de la inversión publicitaria en España.

Morales, A. (2006): "Press subsidies in Spain", en Fernández Alonso, I. et al. (eds.) Press Subsidies in Europe. Barcelona: Departament de la Presidència de la Generalitat de Catalunya.

Sinova, J. (1999): "Las ayudas del Estado a la prensa", en Alonso Hinojal, I. et al. (eds.) Política y Medios de Comunicación. Fundación para el análisis y los estudios sociales. Papeles de la fundación no 53. pp. 235-253. 